\title{
Computational Fluid Dynamics Analysis of Particle Deposition Induced by a Showerhead Electrode in a Capacitively Coupled Plasma Reactor
}

\author{
Ho Jun Kim ${ }^{1, * D}$ and Jung Hwan Yoon ${ }^{2}$ \\ 1 Department of Mechanical Engineering, Gachon University, 1342, Seongnam-daero, Sujeong-gu, \\ Seongnam-si 13120, Korea \\ 2 Department of Mechanical Engineering, Dong-A University, Busan 49315, Korea; 1876612@donga.ac.kr \\ * Correspondence: hojunkim@gachon.ac.kr or tiger.anima@gmail.com
}

Citation: Kim, H.J.; Yoon, J.H. Computational Fluid Dynamics Analysis of Particle Deposition Induced by a Showerhead Electrode in a Capacitively Coupled Plasma Reactor. Coatings 2021, 11, 1004. https://doi.org/10.3390/ coatings11081004

Academic Editor: Eva Pellicer

Received: 30 July 2021

Accepted: 17 August 2021

Published: 23 August 2021

Publisher's Note: MDPI stays neutral with regard to jurisdictional claims in published maps and institutional affiliations.

Copyright: (c) 2021 by the authors. Licensee MDPI, Basel, Switzerland. This article is an open access article distributed under the terms and conditions of the Creative Commons Attribution (CC BY) license (https:// creativecommons.org/licenses/by/ $4.0 /)$.

\begin{abstract}
Defect formation in the deposition of thin films for semiconductors is not yet sufficiently understood. In a showerhead-type capacitively coupled plasma (CCP) deposition reactor, the showerhead acts as both the gas distributor and the electrode. We used computational fluid dynamics to investigate ways to enhance cleanliness by analyzing the particle deposition induced by the showerhead electrode in a CCP reactor. We analyzed particle transport phenomena using a threedimensional complex geometry, whereas $\mathrm{SiH}_{4} / \mathrm{He}$ discharges were simulated in a two-dimensional simplified geometry. The process volume was located between the RF-powered showerhead and the grounded heater. We demonstrated that the efficient transportation of particles with a radius exceeding $1 \mu \mathrm{m}$ onto the heater is facilitated by acceleration inside the showerhead holes. Because the available space in which to flow inside the showerhead is constricted, high gas velocities within the showerhead holes can accelerate particles and lead to inertia-enhanced particle deposition. The effect of the electrode spacing on the deposition of particles generated in plasma discharges was also investigated. Smaller electrode spacing promoted the deposition of particles fed from the showerhead on the heater, whereas larger electrode spacing facilitated the deposition of particles generated in plasma discharges on the heater.
\end{abstract}

Keywords: showerhead electrode; capacitively coupled plasma; plasma-enhanced chemical vapor deposition; computational fluid dynamics; particle transport; fluid simulation; hydrogenated amorphous silicon

\section{Introduction}

In the recent semiconductor industry, the thin film deposition process is often adopted to apply coatings of various layers [1]. Due to the ability to grow uniform films efficiently, plasma-enhanced chemical vapor deposition (PECVD) has been chosen as a mainstream production tool $[2,3]$. In the meantime, because particle contamination (known as defects) causes severe problems during the production of thin films, it should be resolved as much as possible [4]. Thus, in the field of PECVD, defects are one of the major concerns related to the production line because defects adversely affect the product yield [5]. Therefore, an understanding of the formation of defects is highly important in PECVD. The in-line study of defects is an important part of a yield enhancement program, which contributes to the improvement of the product yield through analyzing yield losses. In Hichri et al., it was outlined how yield improvements could be achieved in the dual damascene structure using $\mathrm{Cu} /$ low-k [5]. Since the design rule is shrunken, the short defects in the $\mathrm{Cu}$ line have become potential yield killers. Integrated circuit (IC) manufacturers consider fabrication defects to be the root cause of a lower product yield. In-line inspections, including the detection of scanning defects, classification, and the correction of yield-limiting defects, are important for all critical manufacturing process steps. 
The probability of a particle acting as a "killer defect" depends on both the properties (e.g., the size and position) of the particle and the step at which the "particle deposition" occurred [6]. Thus, it is of great interest to the industry to understand when, where, and how particles are deposited on the surfaces of interest during the manufacturing of semiconductor devices [7-9]. Possible sources of particles in the reactor are dirty gas lines, robotic arms, the door between a process module and a transfer module, and contaminated (or pre-coated) reactor walls.

Showerhead-type capacitively coupled plasma (CCP) PECVD reactors are often considered to be the best configuration for challenging processes [10-12]. To resolve the above-mentioned complex problems about cleanliness, an understanding of the various physical phenomena related to the showerhead electrode is important. This importance comes from the fact that the showerhead acts as not only the gas distributor (being installed between the gas line and the process volume) but also the electrode in a CCP reactor; more specifically, the showerhead has a number of geometrically arranged holes and is used as the upper electrode of the parallel plate reactor. The mixture of gases is fed into the reactor through the showerhead, and the exhaust gas is directly removed from the reactor by the vacuum pump. During PECVD processes, unwanted deposits are accumulated on the inner wall, showerhead, and susceptor surface of the reactor, as well as on other parts of the process kit of the reactor. As these deposits accumulate to reach a certain thickness, the unwanted deposits are exfoliated from the surfaces of the inner walls, showerhead, and the susceptor. The exfoliation of these deposits as foreign objects is responsible for the formation of defects.

Finding a way in which to resolve particle contamination issues in showerhead-type reactors would require the gas flow in each reactor configuration to be analyzed in detail because the particle motion is often strongly correlated with the gas flow field [13-15]. Thus, in related studies, fluid and mass/heat transfer were considered simultaneously in geometries representative of the process tools. Setyawan et al. analyzed the gas flow, heat transfer, and particle transport in a showerhead-type reactor [13]. In their analysis, which included the effects of the gas temperature, they solved the Lagrangian equation of motion to calculate the particle trajectories. More recently, Setyawan et al. experimentally studied particle generation in TEOS $/ \mathrm{O}_{2}$ radio frequency $(\mathrm{RF})$ plasmas [15]. They found that the slow gas flow accelerated particle generation, while the particles were not detected with the fast gas flow.

The above-mentioned considerations motivated our study, which involved numerical investigations of the extent to which particle transport was enhanced by the holes in the showerhead and the effects of the electrode spacing on the particle generation inside a CCP reactor. Therefore, we analyzed the particle transport, for which we opted to use a three-dimensional complex geometry, whereas the $\mathrm{SiH}_{4} / \mathrm{He}$ discharges were simulated in a two-dimensional simplified geometry. As a PECVD case study, we selected to investigate the use of $\mathrm{SiH}_{4} / \mathrm{He}$-based CCP discharges to deposit hydrogenated amorphous silicon (a-Si:H) films. The simulation results were supplemented by conducting a practical PECVD experiment involving the deposition of a hydrogenated amorphous silicon (a-Si:H) film. Despite the importance of computational fluid dynamics (CFD) studies, to the best of our knowledge, CFD studies related to particle deposition pertaining to PECVD have rarely been reported. In particular, studies concerned with the investigation of particle deposition that takes into account the actual reactor configuration, particularly that of the showerhead, have not yet been reported.

\section{Materials and Methods}

In accordance with previous studies, we constructed a self-consistent model for a CCP deposition by considering four major physical phenomena: fluid flow, thermal energy, homogeneous and heterogeneous chemical reactions, and RF discharge. [16,17]. In addition, in this study, we additionally included particle motions to simulate particle deposition [18]. 


\subsection{Mathematical Model for the Gas Flows}

The gas transport is described by the equations below:

$$
\begin{gathered}
\frac{\partial \rho}{\partial t}=-\nabla \cdot(\rho \mathbf{v}) \\
\frac{\partial}{\partial t}(\rho \mathbf{v})=-\nabla \cdot(\rho \mathbf{v} \mathbf{v})-\nabla p_{g}-\nabla \cdot(\boldsymbol{\tau})+\mathbf{f} \\
\boldsymbol{\tau}=-\mu\left[\left(\nabla \mathbf{v}+(\nabla \mathbf{v})^{\mathrm{T}}\right)-\frac{2}{3}(\nabla \cdot \mathbf{v}) \mathbf{I}\right] \\
\rho=\frac{p_{g} M}{R T_{g}} \\
f_{i}=\frac{Y_{i} M}{M_{i}} \\
M=\sum_{i=1}^{N_{m}} f_{i} M_{i}
\end{gathered}
$$

where $\rho$ is the density of the mixture, $t$ is the time, $\mathbf{v}$ is the velocity of the mixture, $p_{g}$ is the gas pressure, $\boldsymbol{\tau}$ is the viscous stress tensor, $\mathbf{f}$ is the net force per unit volume, and $\mu$ is the molecular viscosity. In Equation (3), I represents the unit matrix. $M$ is the molar mass of the mixture, $R$ is the universal gas constant, $T_{g}$ is the gas temperature, $f_{i}$ is the mole fraction of the $i^{\text {th }}$ species, $Y_{i}$ is the mass fraction of the $i^{\text {th }}$ species, $M_{i}$ is the molar mass of the $i^{\text {th }}$ species, and $N_{m}$ is the number of gaseous species in the mixture.

\subsection{Mathematical Model for the Particle Motions}

The motion of a particle is determined by integrating the ordinary differential equations below:

$$
\begin{gathered}
\frac{d \mathbf{x}_{p}}{d t}=\mathbf{v}_{p}, \\
m_{p} \frac{d \mathbf{v}_{p}}{d t}=\mathbf{F}_{p}, \\
\mathbf{F}_{p}=\mathbf{F}_{D}+\mathbf{F}_{G}+\mathbf{F}_{R}+\mathbf{F}_{\text {other }}, \\
m_{p}=\rho_{p} \frac{4}{3} \pi r_{p}^{3}, \\
\frac{d \mathbf{v}_{p}}{d t}=\frac{1}{m_{p}}\left(\mathbf{F}_{D}+\mathbf{F}_{G}+\mathbf{F}_{R}+\mathbf{F}_{\text {other }}\right),
\end{gathered}
$$

where $\mathbf{x}_{p}$ is the particle position, $\mathbf{v}_{p}$ is the particle velocity, $m_{p}$ is the particle mass, $\mathbf{F}_{p}$ is the net force exerted on the particle $(\mathrm{N})$, and $\mathbf{F}_{D}, \mathbf{F}_{G}, \mathbf{F}_{R}$, and $\mathbf{F}_{\text {other }}$ are the drag force $(\mathrm{N})$, gravity force $(\mathrm{N})$, centripetal and Coriolis forces $(\mathrm{N})$, and any additional forces acting on the particle, respectively. In Equation (10), $\rho_{p}$ is the particle density, and $r_{p}$ is the particle radius.

In this study, it is important to take the aerodynamic drag force on a particle into consideration; thus, we calculate the drag force using the equations below:

$$
\begin{gathered}
\mathbf{F}_{D}=\frac{1}{2} C_{D} \rho A_{p}\left|\mathbf{v}-\mathbf{v}_{p}\right|\left(\mathbf{v}-\mathbf{v}_{p}\right), \\
A_{p}=\frac{\pi d_{p}^{2}}{4} \\
\operatorname{Re}_{p}=\frac{\rho\left|\mathbf{v}-\mathbf{v}_{p}\right| d_{p}}{\mu}
\end{gathered}
$$


where $C_{D}$ is the drag coefficient, $A_{p}$ is the area of the particle projected in the flow direction, $d_{p}$ is the particle diameter, and $\operatorname{Re}_{p}$ is the relative Reynolds number [18].

\subsection{Mathematical Model for Heat Transfer and Multi-Component Transport}

The equations for the heat transfer and multi-component transport are shown as below:

$$
\begin{gathered}
\frac{\partial\left(\rho c_{p} T_{g}\right)}{\partial t}=-\nabla \cdot\left(-k_{c} \nabla T_{g}+\rho c_{p} \mathbf{v} T_{g}\right)-p_{g}(\nabla \cdot \mathbf{v})+(\boldsymbol{\tau} \cdot \nabla \mathbf{v})+S_{h}+D_{h} \\
D_{h}=\nabla \cdot\left(R T_{g} \sum_{i=1}^{N_{m}} \frac{D_{i}^{T}}{M_{i} f_{i}} \nabla f_{i}\right) \\
D_{i}^{T}=\alpha D_{i} M_{i} M_{j} c_{g}^{2} / \rho \\
\frac{\partial}{\partial t}\left(\rho Y_{i}\right)=-\nabla \cdot\left(\rho \mathbf{v} Y_{i}\right)-\nabla \cdot\left(j_{i}^{C}+j_{i}^{T}\right)+\left(G_{i}-L_{i}\right) M_{i},
\end{gathered}
$$

where $c_{p}$ is the specific heat of the gas mixture, $k_{c}$ is the thermal conductivity of the gas mixture, $S_{h}$ is the heat of the chemical reaction, $D_{h}$ is the heat generated by the Dufour effect, $D_{i}^{T}$ is the thermal diffusion coefficient of the $i^{\text {th }}$ species, $\alpha$ is the thermal diffusion factor, $D_{i}$ is the diffusion coefficient of the $i^{\text {th }}$ species, $M_{j}$ is the molar mass of the $j^{\text {th }}$ species, $c_{g}$ is the gas concentration, $j_{i}{ }^{C}$ is the flux of the $i^{\text {th }}$ species due to the concentration gradients, $j_{i}^{T}$ is the thermal diffusion flux of the $i^{\text {th }}$ species, $G_{i}$ is the rate at which the $i^{\text {th }}$ species is formed, and $L_{i}$ is the rate at which the $i^{\text {th }}$ species is depleted.

\subsection{Mathematical Model for the Plasma Discharges}

Using a drift-diffusion approximation for the flux, the continuity in the electron density is considered by solving:

$$
\begin{gathered}
\frac{\partial n_{e}}{\partial t}+\nabla \cdot J_{e}=S_{e}, \\
J_{e}=-D_{e} \nabla n_{e}+\mu_{e} n_{e} \nabla \phi,
\end{gathered}
$$

where $n_{e}$ is the electron density, $J_{e}$ is the electron flux, $S_{e}$ is the electron source, $D_{e}$ is the electron diffusion coefficient, $\mu_{e}$ is the electron mobility, and $\phi$ is the electric potential.

The electron energy balance is considered by solving:

$$
\frac{\partial\left(n_{e} \varepsilon\right)}{\partial t}+\nabla \cdot\left[\frac{5}{3} n_{e} \varepsilon \mathbf{v}_{e}-\frac{5}{3} n_{e} D_{e} \nabla \varepsilon\right]=S_{\varepsilon}
$$

where $\varepsilon$ is the electron energy and $\mathbf{v}_{e}$ is the electron velocity, and $S_{\varepsilon}$ is the electron energy source term.

The energy transferred from an ion to a neutral species is determined by the equation below:

$$
\varepsilon_{i}=\frac{e}{\mu_{i}} n_{i} v_{i}^{2}
$$

where $e$ is the elementary charge, $\mu_{i}$ is the ion mobility, $n_{i}$ is the ion density, and $v_{i}$ is the magnitude of the velocity vector of an ion.

\subsection{Numerical Scheme}

For the particle transport simulations, we used the commercial CFD software (version 5.0) package Simerics (Simerics Inc., Bellevue, WA, USA) [19]. The program.solves gas flows (continuity and momentum conservation), particle motions (based on the Lagrangian approach), heat transfer (energy conservation), and multi-component transport (species conservation), and the corresponding governing equations are those in Equations (1)-(18). These equations were discretized by using the finite volume formulation. The pressure- 
velocity coupling was computed with the semi-implicit method for the pressure-linked equations (SIMPLE) algorithm, following Patankar [20]. The 2nd order upwind scheme was chosen for spatial discretization. The application of accurate flow field solutions to particle deposition simulations is highly important; therefore, the non-isothermal flow solutions from Simerics were validated by comparing them with the simulation results from the code of an in-house spectral element method [21]. This approach enabled us to conduct 3D simulations of the gas flow of a non-isothermal mixture to consider the hydrodynamic effects induced as a result of the complicated geometry of the structure of the gas distribution assembly (see Figure 1).

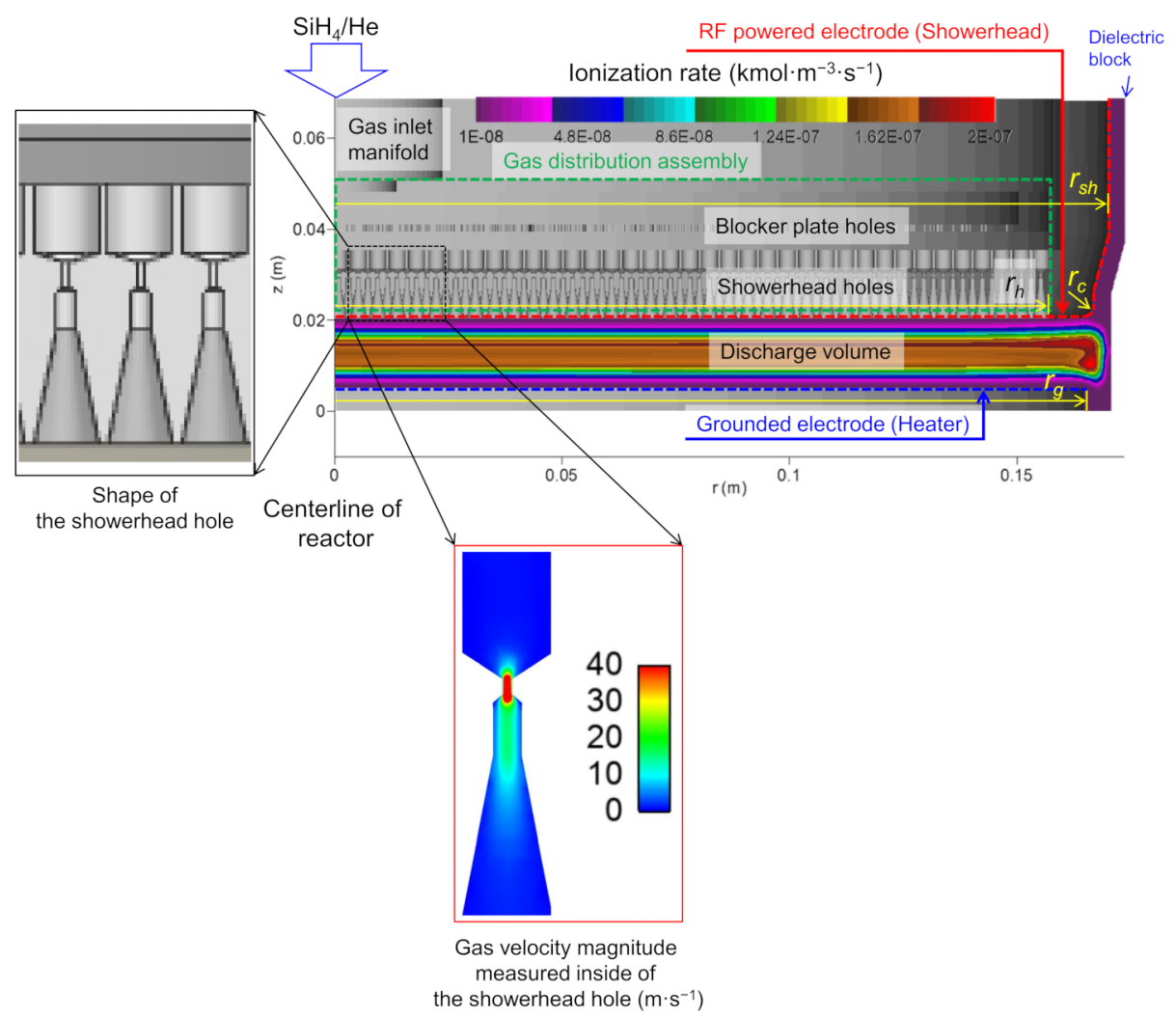

Figure 1. CCP reactor configuration plotted together with the spatial variation of the time-averaged ionization rate $\left(\mathrm{kmol} \cdot \mathrm{m}^{-3} \cdot \mathrm{s}^{-1}\right)$. The magnitude of the gas velocity measured inside the showerhead hole is shown. The reactor dimensions are also indicated.

For the CCP discharge simulations, we used the commercial multi-physics software (version 2020.0) package CFD-ACE+ (ESI CFD Inc. and CFD Research Corp., Huntsville, $\mathrm{AL}, \mathrm{USA}$ ) [22]. In multiple previous cases, $\mathrm{CCP}$ discharges were successfully simulated using $\mathrm{CFD}-\mathrm{ACE}+$, and their results were validated by comparing them with experimental observations [23,24]. The control volume-based method was used to discretize the governing equations. The Scharfetter-Gummel method (exponential scheme) was chosen for the spatial discretization of the governing equations for discharges (electron and electron energy conservation equations). Because non-Maxwellian electron energy distribution functions (EEDFs) were expected for the $\mathrm{SiH}_{4} / \mathrm{He}$ discharges in the given torr regime, the electron transport coefficients and the electron impact reaction rates were calculated separately. For this separated calculation of the EEDFs, we solved the 0D Boltzmann equation first and built a lookup table. The data in the lookup table were simultaneously adopted in the simulations of the CCP discharges. 


\subsection{Computational Mesh}

To enable the three-dimensional simulation of particle transport, the fluid volume was divided into many small control volumes. For this preprocess (meshing) step, we used the Simerics grid generator based on a body-fitted binary tree approach [19]. Because the majority of the cells are cubes and the cells are hexagonal (not deformed), the skewness of the mesh is zero. In addition, Simerics can create a grid by setting the aspect ratio. The mesh used in this study was set to a cell with an aspect ratio of 1 [19]. Based on the mesh convergence test, the optimal total number of mesh elements was determined to be 53.8 million: the relative residuals were kept below $10^{-4}$. Therefore, enough grids were used to minimize errors depending on the mesh quality.

\subsection{Reactor Geometry and Problem Settings}

Figure 1 shows the axisymmetric volume of our showerhead-type CCP reactor, which can be analyzed on the $r$-z plane, where $r$ is the radial coordinate, whereas $z$ is the axial coordinate. The upper electrode is powered by radio frequency (RF; $13.56 \mathrm{MHz}$ ), whereas the lower electrode is grounded. As the lower electrode is often heated to high temperatures (e.g., $T_{h}>500 \mathrm{~K}$ ), it is referred to as the heater. The upper electrode also plays the role of a gas distribution assembly that normally consists of multiple perforated plates.

In Figure 1, one can observe that the first of these plates is the blocker plate, and the second is the showerhead. The showerhead communicates directly with the plasma volume and uniformly distributes the source gases over the lower electrode upon their introduction into the plasma volume. When the plasma distribution is uniform, uniform gas distribution is also necessary to obtain a uniform-surface flux on the heater. Note that, based on a previous experimental study, the holes in the showerhead have the shape of a converging-diverging nozzle to enhance the uniformity of the gas distribution. As shown in Figure 1, each showerhead hole is pinched in the middle such that the hole has the shape of an hourglass. Owing to this shape, the gas flow is accelerated in the middle: the figure shows the gas velocity magnitude that was measured inside of the showerhead hole.

The particle transport simulations were conducted using a three-dimensional complex geometry (i.e., we mimicked the geometry of a real reactor; see Figure 1), whereas the CCP simulations were carried out using a simplified two-dimensional geometry, which is computationally less demanding and lowered the high computational cost. For the CCP discharge simulations, we simply assumed that the $\mathrm{SiH}_{4} / \mathrm{He}$ mixtures were provided through an inlet boundary of the plasma volume, which corresponds to the outlet of the gas distribution assembly in a radially uniform manner, instead of passing through a series of showerhead holes.

The input conditions in the 18 cases considered in this study are listed in Table 1. Although not indicated in the table, for all cases, the sidewall temperature $\left(T_{s w}\right)$ and heater temperature $\left(T_{h}\right)$ were commonly set to 423 and $673 \mathrm{~K}$, respectively. To observe the effects of the electrode spacing $(d)$ on the particle generation in CCP discharges, in Cases 17 and 18, the electrode spacings were set to 7 and $15 \mathrm{~mm}$, respectively. The contour in Figure 1 depicts the spatial distribution of the time-averaged ionization rate for Case 1. Its off-axis maximum exists just beside the heater edge due to the enhanced electric field near the electrode edge. 
Table 1. List of cases considered in this study. We analyzed particle transport phenomena using a three-dimensional complex geometry, whereas $\mathrm{SiH}_{4} / \mathrm{He}$ discharges were simulated in a two-dimensional simplified geometry.

\begin{tabular}{|c|c|c|c|c|c|c|c|c|}
\hline $\begin{array}{l}\text { Case } \\
\text { No. }\end{array}$ & Physics & $\begin{array}{c}\text { Geo-Metry } \\
\text { (Mesh) }\end{array}$ & $\begin{array}{c}\text { Showerhead } \\
\text { Temp. } \\
\left(T_{\text {sh }}, \mathrm{K}\right)\end{array}$ & $\begin{array}{c}\text { RF } \\
\text { Power } \\
\left(P_{R F}, W\right)\end{array}$ & $\begin{array}{c}\text { Gas } \\
\text { Pressure } \\
\left(p_{g}, \mathrm{~Pa}\right)\end{array}$ & $\begin{array}{c}\mathrm{SiH}_{4} / \mathrm{He} \\
\text { Flows } \\
\text { (sccm) }\end{array}$ & $\begin{array}{c}\text { Particle } \\
\text { Density } \\
\left(\mathrm{kg} \cdot \mathrm{m}^{-3}\right) \\
\text { and Size (m) }\end{array}$ & $\begin{array}{c}\text { Electrode } \\
\text { Spacing } \\
(d, \mathrm{~mm})\end{array}$ \\
\hline 1 & Discharges & $2 \mathrm{D}$ & 673 & 10 & 400 & $50 / 5000$ & - & 15 \\
\hline 2 & Discharges & $2 \mathrm{D}$ & 673 & 400 & 400 & $50 / 5000$ & - & 15 \\
\hline 3 & Gas flows & $3 \mathrm{D}$ & 673 & - & 400 & $50 / 5000$ & $2329,2 \times 10^{-6}$ & 9 \\
\hline 4 & Gas flows & $3 \mathrm{D}$ & 673 & - & 400 & $50 / 5000$ & $2329,4 \times 10^{-6}$ & 9 \\
\hline 5 & Gas flows & $3 \mathrm{D}$ & 673 & - & 400 & $50 / 5000$ & $2329,6 \times 10^{-6}$ & 9 \\
\hline 6 & Gas flows & $3 \mathrm{D}$ & 673 & - & 400 & $50 / 5000$ & $2329,2 \times 10^{-6}$ & 15 \\
\hline 7 & Gas flows & $3 \mathrm{D}$ & 673 & - & 400 & $50 / 5000$ & $2329,4 \times 10^{-6}$ & 15 \\
\hline 8 & Gas flows & $3 \mathrm{D}$ & 673 & - & 400 & $50 / 5000$ & $2329,6 \times 10^{-6}$ & 15 \\
\hline 9 & Gas flows & $3 \mathrm{D}$ & 673 & - & 400 & $50 / 5000$ & $2650,2 \times 10^{-6}$ & 9 \\
\hline 10 & Gas flows & $3 \mathrm{D}$ & 673 & - & 400 & $50 / 5000$ & $2650,4 \times 10^{-6}$ & 9 \\
\hline 11 & Gas flows & $3 \mathrm{D}$ & 673 & - & 400 & $50 / 5000$ & $2650,6 \times 10^{-6}$ & 9 \\
\hline 12 & Gas flows & $3 \mathrm{D}$ & 673 & - & 400 & $50 / 5000$ & $2650,2 \times 10^{-6}$ & 15 \\
\hline 13 & Gas flows & $3 \mathrm{D}$ & 673 & - & 400 & $50 / 5000$ & $2650,4 \times 10^{-6}$ & 15 \\
\hline 14 & Gas flows & $3 \mathrm{D}$ & 673 & - & 400 & $50 / 5000$ & $2650,6 \times 10^{-6}$ & 15 \\
\hline 15 & Discharges & $2 \mathrm{D}$ & 473 & 100 & 800 & $100 / 5000$ & - & 15 \\
\hline 16 & Discharges & $2 \mathrm{D}$ & 473 & 100 & 800 & $100 / 5000$ & - & 20 \\
\hline 17 & Discharges & $2 \mathrm{D}$ & 473 & 100 & 2400 & $100 / 5000$ & - & 7 \\
\hline 18 & Discharges & $2 \mathrm{D}$ & 473 & 100 & 2400 & $100 / 5000$ & - & 15 \\
\hline
\end{tabular}

\section{Results}

As stated above, a dirty gas line can be an important source of contamination because the impurities can be delivered to the gas distribution assembly and accumulate inside this assembly. In addition, source gases such as $\mathrm{SiH}_{4}$ and TEOS can contaminate the interior walls of the gas distribution assembly at higher gas pressure $[25,26]$. This section presents our analysis of the transportation of particles from the gas distribution assembly to the heater surface.

\subsection{Gas Flows in a CCP Reactor}

To simulate particle transport in a three-dimensional complex geometry, we omitted the consideration of CCP discharges because of the extremely high computational cost that would be incurred. Because the energy equations for solving the gas temperature $\left(T_{g}\right)$ in the simulations are given as Equations (15) and (22), the use of ion currents to heat the gas would increase the gas temperature significantly. Thus, the distribution of the gas flow stream and velocity magnitude is often updated by the plasma, as discussed in the case of inductively coupled plasma. This contribution of the ion currents makes it necessary to consider the gas heating effects of plasma discharges in an analysis of the particle transport inside a CCP reactor because the positions of particles are calculated from the gas velocity information (see Equations (1)-(18)). However, under our process conditions, the effect of the charged species on the gas temperature is negligible. The important reasons for this simplification are as follows: First, our reactor is constructed under non-isothermal wall boundary conditions with a large temperature difference (i.e., $T_{h}-T_{s w}=250 \mathrm{~K}$ ). Second, the input RF power is less than 1000 W. Finally, the fractions of charged species are low (i.e., the electron number fraction is less than $10^{-7}$ ). Therefore, particle transport is determined by the gas flow field, which is updated mainly by the non-isothermal wall boundary conditions.

In fact, in a case similar to ours, Agarwal et al. numerically demonstrated that spatial variations in the gas temperature can be largely induced by interactions with ions in the CCP etching reactor [27]. However, their process parameters were set differently to ours: the gas pressure was set to $p_{g}=400 \mathrm{~Pa}$ in this study, whereas they used 
$p_{g}=50 \mathrm{mTorr}\left(\approx 6.7 \mathrm{~Pa}\right.$, low-pressure conditions); the input power was set to $P_{R F}=100 \mathrm{~W}$ in this study, whereas they used $P_{R F}=500-3000 \mathrm{~W}$; and finally, the electrode spacing was set to $d=0.015 \mathrm{~m}$ in this study, whereas they used $d=0.032 \mathrm{~m}$. In addition, it is worth noting that the thermal conductivity of the dilution gas $(\mathrm{He})$ is $k_{c}=0.151 \mathrm{~W} \cdot \mathrm{m}^{-1} \cdot \mathrm{K}^{-1}$ at $300 \mathrm{~K}$ in this study, whereas the thermal conductivity of the dilution gas (Ar) used by Agarwal et al. was only $k_{c}=0.018 \mathrm{~W} \cdot \mathrm{m}^{-1} \cdot \mathrm{K}^{-1}$ at $300 \mathrm{~K}$. Thus, in this study, the gas temperature distribution is determined by the non-isothermal wall boundary condition rather than by ion current heating.

Therefore, based on the aforementioned reasons, we can simulate the particle transport without consideration of the $\mathrm{CCP}$ discharges. Figure 2 depicts the results related to the gas transport parameters in cases with CCP discharges. To clarify the comparison, Cases $1\left(P_{R F}=10 \mathrm{~W}\right)$ and $2\left(P_{R F}=400 \mathrm{~W}\right)$ were scrutinized. The electron density, gas velocity magnitude, and gas temperature were selected for analysis on the basis of their significance under our given process conditions. Although Figure 2a,b depicts that a comparison of spatial distributions of the electron density demonstrates the significant difference, the differences in the magnitude of the gas velocity and gas temperature distributions are negligibly small, as depicted in Figure 2c-f. This comparison clearly indicates that the gas transport phenomena are not affected by the CCP discharges in this study. Note that in these two cases, it is commonly observed that the gas inertia allows the formation of "dead zones" in the corners near the gas outlet, with the radial positions of these zones located between the edges of the electrode and the sidewall. The existence of these dead zones means that particles are easily deposited and accumulated near the heater edge.

(a)

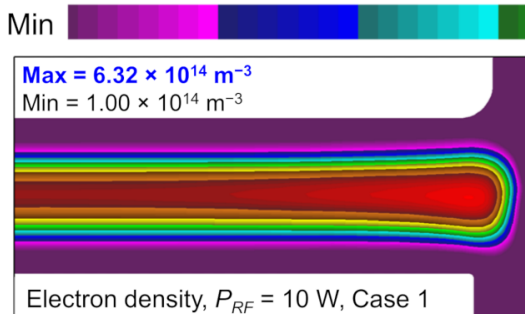

0.12

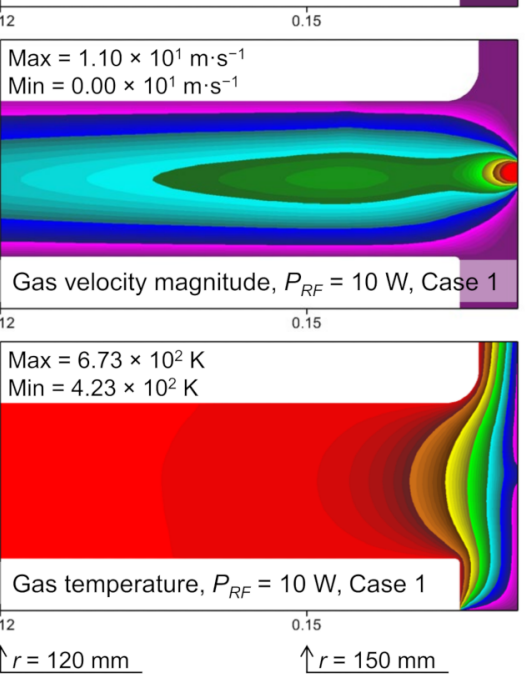

(b)

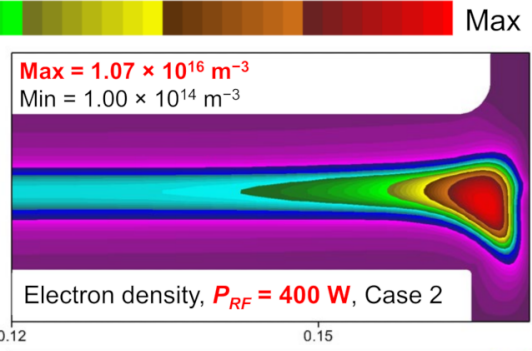

(d)
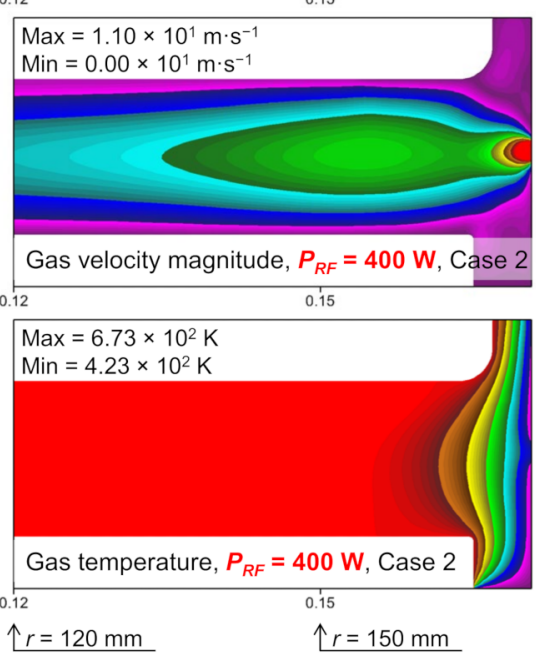

Figure 2. Contour plots of the spatial profiles of the time-averaged electron density $\left(\mathrm{m}^{-3}\right)$ for (a) Case $1\left(P_{R F}=10 \mathrm{~W}\right)$ and $(\mathbf{b})$ Case $2\left(P_{R F}=400 \mathrm{~W}\right)$ for $r \geq 120 \mathrm{~mm}$. Contour plots for the spatial profiles of the gas velocity $\left(\mathrm{m} \cdot \mathrm{s}^{-1}\right)$ for $(\mathbf{c})$ Case $1\left(P_{R F}=10 \mathrm{~W}\right)$ and $(\mathbf{d})$ Case $2\left(P_{R F}=400 \mathrm{~W}\right)$ for $r \geq 120 \mathrm{~mm}$. Contour plots for the spatial profiles of the gas temperature $(\mathrm{K})$ for $(\mathbf{e})$ Case $1\left(P_{R F}=10 \mathrm{~W}\right)$ and $(\mathbf{f})$ Case $2\left(P_{R F}=400 \mathrm{~W}\right)$ for $r \geq 120 \mathrm{~mm}$. The profiles are radially uniform for $r<120 \mathrm{~mm}$. 


\subsection{Analysis of Gas Flows in a Three-Dimensional Geometry}

In this section, we present our results of the gas flow simulation in a three-dimensional complex geometry. The flow streamlines, i.e., the directions in which the gas fluid flows, are shown in Figure 3a for Case $3\left(r_{p}=2.0 \times 10^{-6} \mathrm{~m}, d=9 \mathrm{~mm}\right)$, and in Figure $3 \mathrm{~b}, \mathrm{c}$, the distributions of the magnitude of the gas velocity and the gas pressure are shown, respectively. Note that the highly accelerated gases are fed through a centrally positioned narrow gas line (i.e., the gas inlet manifold in Figure 1). The inlet gases flow rapidly, with a high Reynolds number $\operatorname{Re}=\rho U L / \mu$, where $\rho$ is the density, $U$ is the characteristic velocity, $L$ is the characteristic length, and $\mu$ is the dynamic viscosity.

(a)

(b)

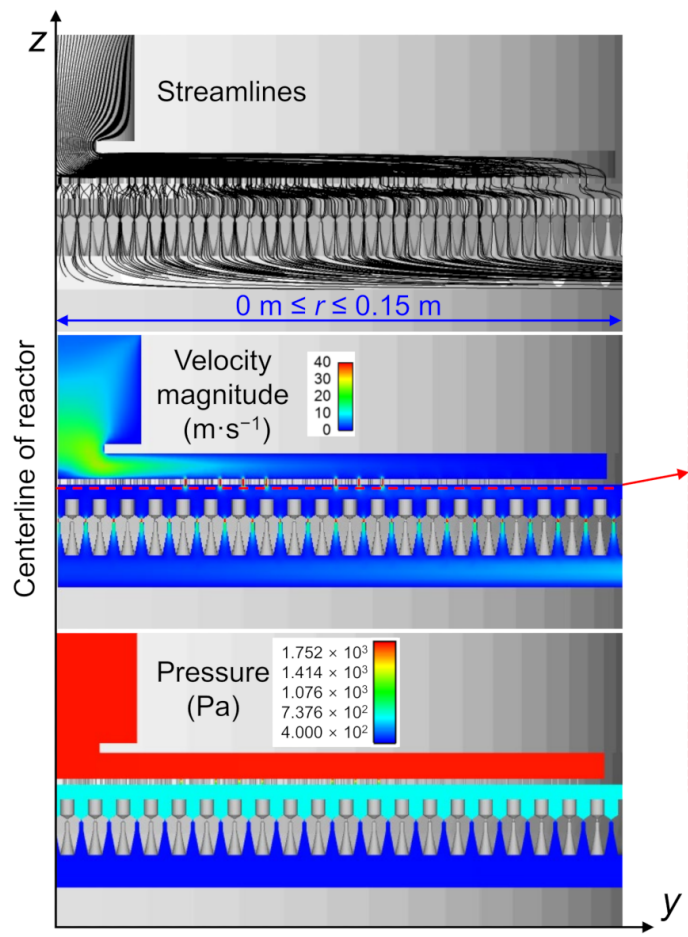

$\begin{array}{cc}\text { Velocity } & 4.00 \\ \text { magnitude } & 2.00 \\ \left(\mathrm{~m} \cdot \mathrm{s}^{-1}\right) & 1.00 \\ & 0.00\end{array}$

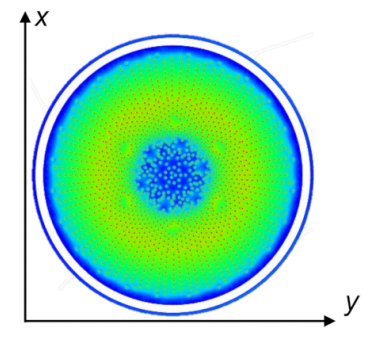

Velocity magnitude measured

between the blocker plate and the showerhead

Figure 3. Results of the 3D gas flow simulation for Case $3\left(r_{p}=2.0 \times 10^{-6} \mathrm{~m}, d=9 \mathrm{~mm}\right)$ : (a) streamlines; contour plots of the (b) gas velocity and (c) gas pressure. It is observed that the streamlines of the interim space between the blocker plate and showerhead are most curled at the center of the reactor $(r \leq 50 \mathrm{~mm})$ owing to the effect of the high Reynolds number.

The blocker plate and the showerhead are installed to suppress the "tangled gas flow structure", which can be observed when a large amount of inlet gas is supplied and forced to rotate because of both the inertia of motion and the abrupt change in the flow direction. The blocker plate is generally a flat component with many very small apertures (holes) to disperse the inlet gases uniformly into the interim space between the blocker plate and showerhead. This mechanism is effective as a result of a growing decrease in the gas pressure, $\Delta p_{g}$, as shown in Figure 3c.

If the streamlines begin from the inlet of the process volume, their initial directions are nearly normal to the showerhead surface. These normal directions originate from the fact that the showerhead holes accelerate gas flows and the radial component of the gas velocity is negligible near the showerhead surface, although the gas pressure is much lower than the atmospheric pressure $\left(p_{g}<<p_{a t m}\right)$. When the gas flow reaches a certain point, which is not far from its starting point, the direction of the streamline is largely changed. These streamlines are folded and inclined because the gas is being pumped radially outward and because of the presence of the heater surface, with the flow becoming nearly parallel to the heater surface. These large changes can enhance the deposition of particles on the heater surface owing to the inertial effects of massive particles, as shown later. As a result 
of the low gas pressure, flow separations or large vortices are not created between the showerhead and the heater. As a result, "stagnation-point flow" characteristics (the fluid flow associated with uniform injection impinging on a perpendicular wall) are clearly demonstrated.

\subsection{Particle Deposition}

By varying the particle radius $\left(r_{p}\right)$, the particle density $\left(\rho_{p}\right)$, and the electrode spacing $(d)$, for Cases $3\left(r_{p}=2.0 \times 10^{-6} \mathrm{~m}, \rho_{p}=2329 \mathrm{~kg} \cdot \mathrm{m}^{-3}, d=9 \mathrm{~mm}\right), 4\left(r_{p}=4.0 \times 10^{-6} \mathrm{~m}\right.$, $\left.\rho_{p}=2329 \mathrm{~kg} \cdot \mathrm{m}^{-3}, d=9 \mathrm{~mm}\right)$, and $5\left(r_{p}=6.0 \times 10^{-6} \mathrm{~m}, \rho_{p}=2329 \mathrm{~kg} \cdot \mathrm{m}^{-3}, d=9 \mathrm{~mm}\right)$, Cases $6\left(r_{p}=2.0 \times 10^{-6} \mathrm{~m}, \rho_{p}=2329 \mathrm{~kg} \cdot \mathrm{m}^{-3}, d=15 \mathrm{~mm}\right), 7\left(r_{p}=4.0 \times 10^{-6} \mathrm{~m}, \rho_{p}=2329 \mathrm{~kg} \cdot \mathrm{m}^{-3}\right.$, $d=15 \mathrm{~mm})$, and $8\left(r_{p}=6.0 \times 10^{-6} \mathrm{~m}, \rho_{p}=2329 \mathrm{~kg} \cdot \mathrm{m}^{-3}, d=15 \mathrm{~mm}\right)$, Cases $9\left(r_{p}=2.0 \times 10^{-6} \mathrm{~m}\right.$, $\left.\rho_{p}=2650 \mathrm{~kg} \cdot \mathrm{m}^{-3}, d=9 \mathrm{~mm}\right), 10\left(r_{p}=4.0 \times 10^{-6} \mathrm{~m}, \rho_{p}=2650 \mathrm{~kg} \cdot \mathrm{m}^{-3}, d=9 \mathrm{~mm}\right)$, and $11\left(r_{p}=6.0 \times 10^{-6} \mathrm{~m}, \rho_{p}=2650 \mathrm{~kg} \cdot \mathrm{m}^{-3}, d=9 \mathrm{~mm}\right)$, and Cases $12\left(r_{p}=2.0 \times 10^{-6} \mathrm{~m}\right.$, $\left.\rho_{p}=2650 \mathrm{~kg} \cdot \mathrm{m}^{-3}, d=15 \mathrm{~mm}\right), 13\left(r_{p}=4.0 \times 10^{-6} \mathrm{~m}, \rho_{p}=2650 \mathrm{~kg} \cdot \mathrm{m}^{-3}, d=15 \mathrm{~mm}\right)$, and $14\left(r_{p}=6.0 \times 10^{-6} \mathrm{~m}, \rho_{p}=2650 \mathrm{~kg} \cdot \mathrm{m}^{-3}, d=15 \mathrm{~mm}\right)$, we simulated the particle trajectories using inertial particles from the initial positions, and their results are depicted in Figure 4 (Cases 3, 4, and 5), Figure 5 (Cases 6, 7, and 8), Figure 6 (Cases 9, 10, and 11), and Figure 7 (Cases 12, 13, and 14). As stated above, because the showerhead electrode has many very small holes, this complex structure induces a large change in the gas pressure, $\Delta p_{g}$, as shown in Figure 3c. The increased gas pressure enables source gases such as $\mathrm{SiH}_{4}$ and TEOS to contaminate the interior walls of the gas distribution assembly.

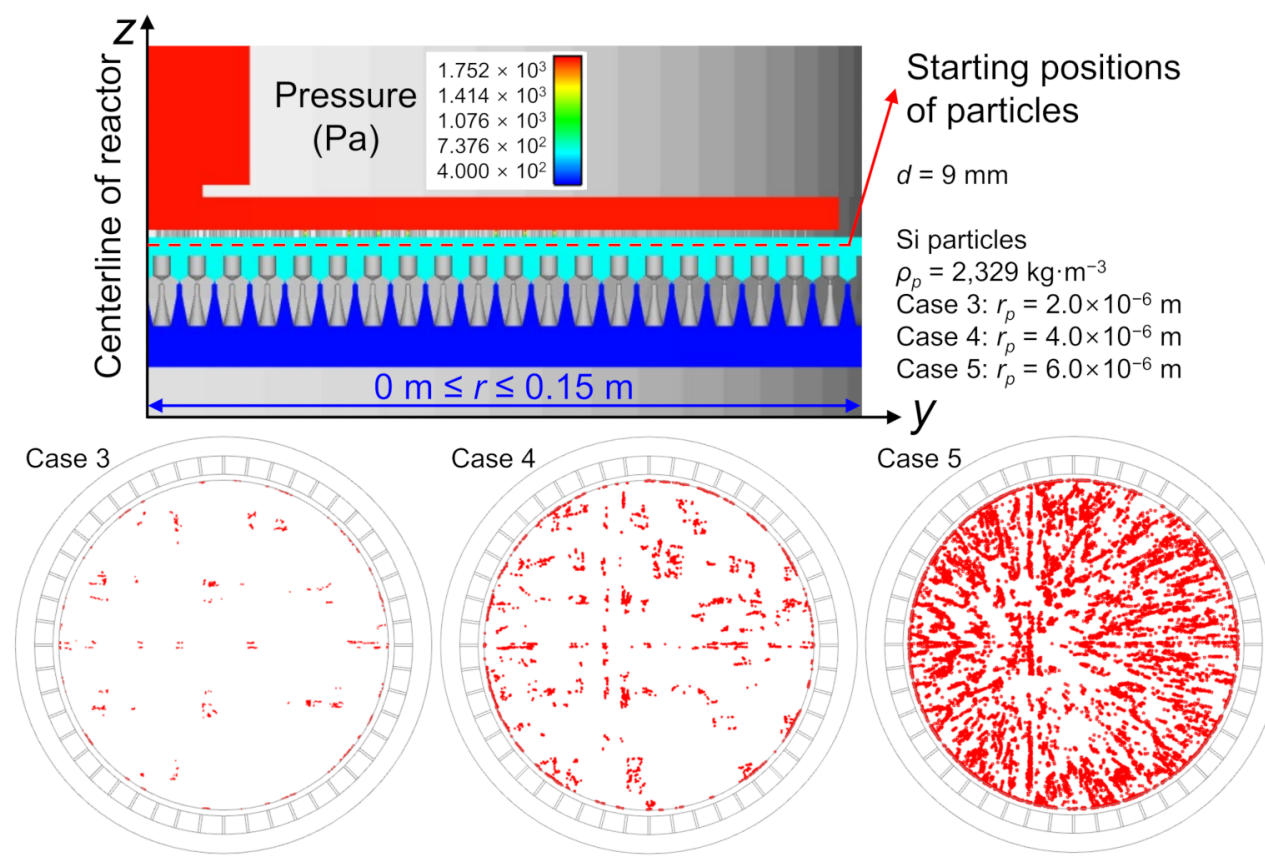

Figure 4. Starting positions of inertial particles are indicated. The spatial variation in the gas pressure $\left(p_{g}, \mathrm{~Pa}\right)$ is plotted together for Case 3. Final positions of particles deposited on the heater surface depicted for Case $3\left(r_{p}=2.0 \times 10^{-6} \mathrm{~m}, \rho_{p}=2329 \mathrm{~kg} \cdot \mathrm{m}^{-3}, d=9 \mathrm{~mm}\right)$, Case $4\left(r_{p}=4.0 \times 10^{-6} \mathrm{~m}\right.$, $\left.\rho_{p}=2329 \mathrm{~kg} \cdot \mathrm{m}^{-3}, d=9 \mathrm{~mm}\right)$, and Case $5\left(r_{p}=6.0 \times 10^{-6} \mathrm{~m}, \rho_{p}=2329 \mathrm{~kg} \cdot \mathrm{m}^{-3}, d=9 \mathrm{~mm}\right)$. 


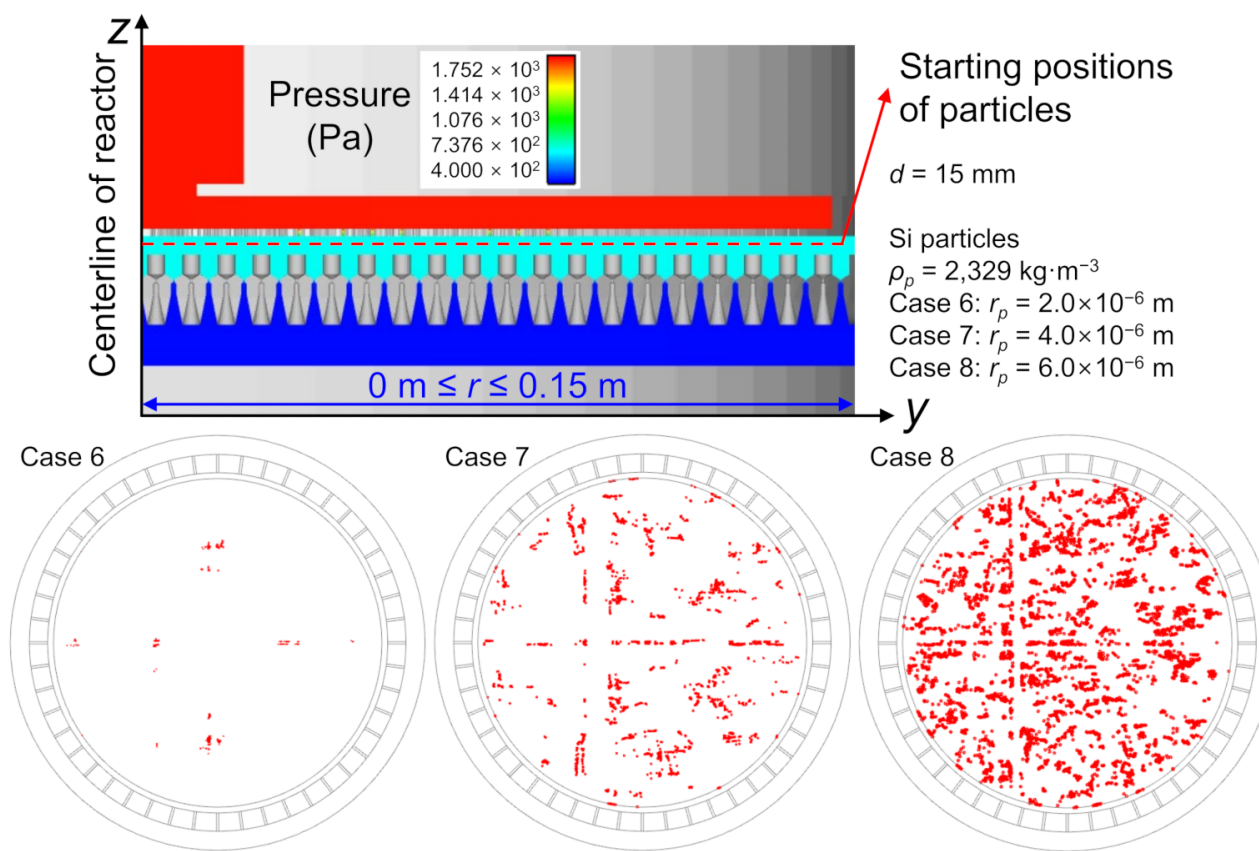

Figure 5. Starting positions of inertial particles are indicated. The spatial variation in the gas pressure $\left(p_{g}, \mathrm{~Pa}\right)$ is plotted together for Case 3. Final positions of particles deposited on the heater surface depicted for Case $6\left(r_{p}=2.0 \times 10^{-6} \mathrm{~m}, \rho_{p}=2329 \mathrm{~kg} \cdot \mathrm{m}^{-3}, d=15 \mathrm{~mm}\right)$, Case $7\left(r_{p}=4.0 \times 10^{-6} \mathrm{~m}\right.$, $\left.\rho_{p}=2329 \mathrm{~kg} \cdot \mathrm{m}^{-3}, d=15 \mathrm{~mm}\right)$, and Case $8\left(r_{p}=6.0 \times 10^{-6} \mathrm{~m}, \rho_{p}=2329 \mathrm{~kg} \cdot \mathrm{m}^{-3}, d=15 \mathrm{~mm}\right)$.

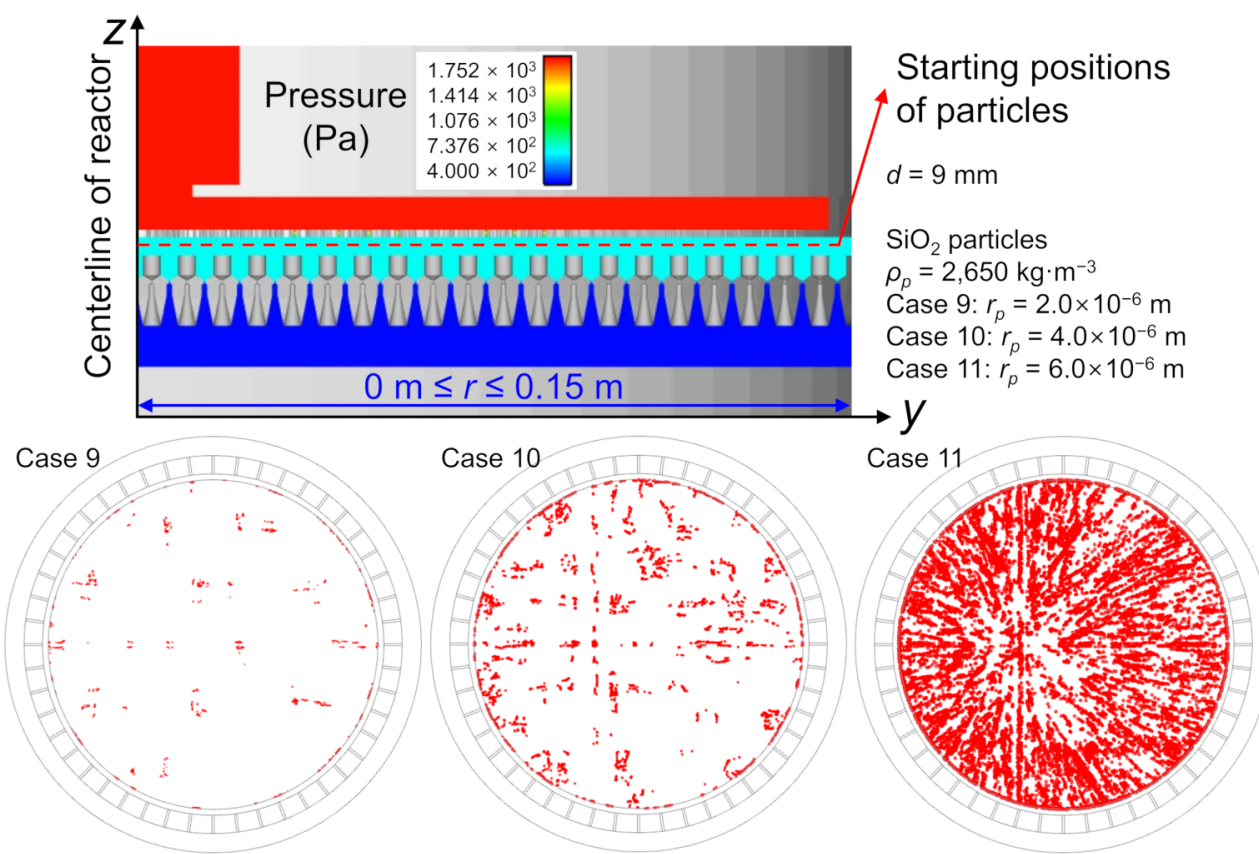

Figure 6. Starting positions of inertial particles are indicated. The spatial variation in the gas pressure $\left(p_{g}, \mathrm{~Pa}\right)$ is plotted together for Case 3 . Final positions of particles deposited on the heater surface depicted for Case $9\left(r_{p}=2.0 \times 10^{-6} \mathrm{~m}, \rho_{p}=2650 \mathrm{~kg} \cdot \mathrm{m}^{-3}, d=9 \mathrm{~mm}\right)$, Case $10\left(r_{p}=4.0 \times 10^{-6} \mathrm{~m}\right.$, $\left.\rho_{p}=2650 \mathrm{~kg} \cdot \mathrm{m}^{-3}, d=9 \mathrm{~mm}\right)$, and Case $11\left(r_{p}=6.0 \times 10^{-6} \mathrm{~m}, \rho_{p}=2650 \mathrm{~kg} \cdot \mathrm{m}^{-3}, d=9 \mathrm{~mm}\right)$. 


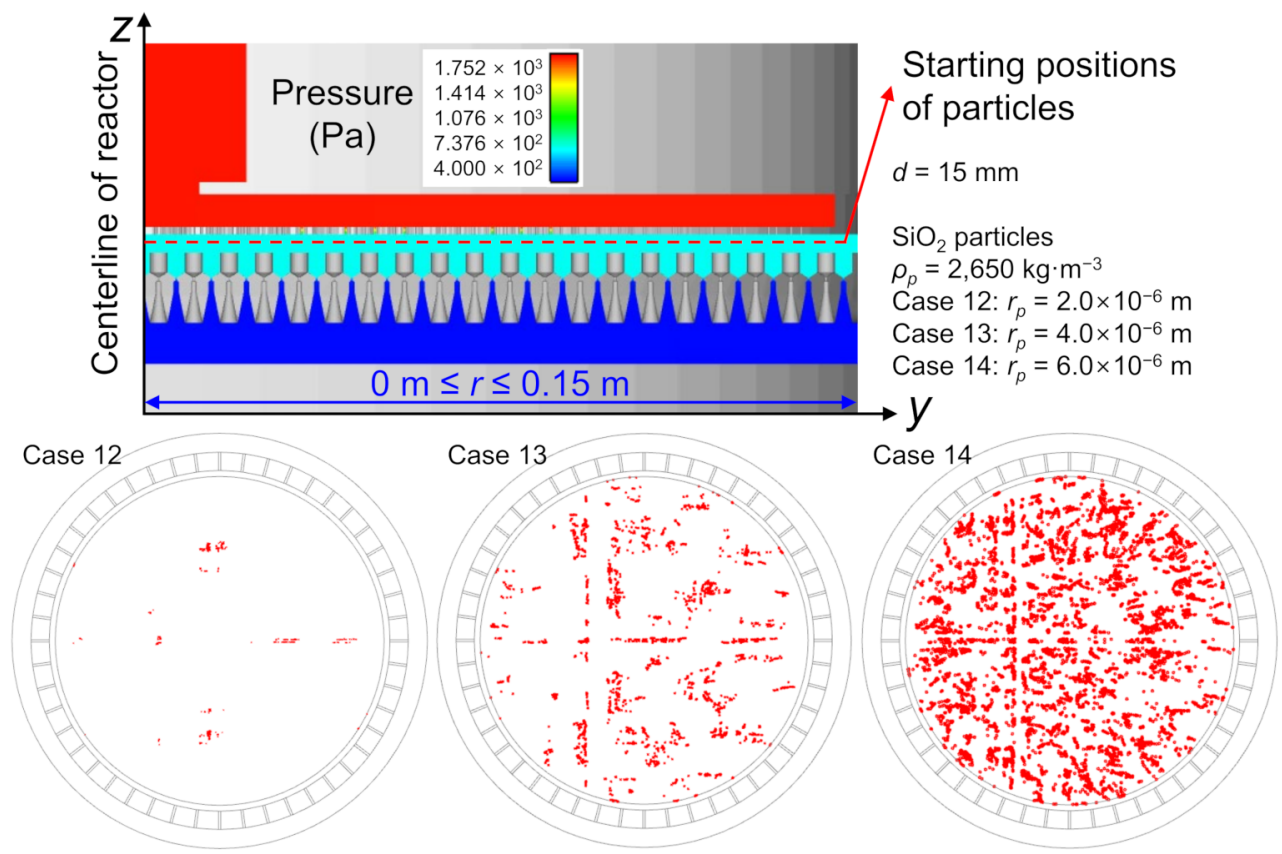

Figure 7. Starting positions of inertial particles are indicated. The spatial variation in the gas pressure $\left(p_{g}, \mathrm{~Pa}\right)$ is plotted together for Case 3. Final positions of particles deposited on the heater surface depicted for Case $12\left(r_{p}=2.0 \times 10^{-6} \mathrm{~m}, \rho_{p}=2650 \mathrm{~kg} \cdot \mathrm{m}^{-3}, d=15 \mathrm{~mm}\right)$, Case $13\left(r_{p}=4.0 \times 10^{-6} \mathrm{~m}\right.$, $\left.\rho_{p}=2650 \mathrm{~kg} \cdot \mathrm{m}^{-3}, d=15 \mathrm{~mm}\right)$, and Case $14\left(r_{p}=6.0 \times 10^{-6} \mathrm{~m}, \rho_{p}=2650 \mathrm{~kg} \cdot \mathrm{m}^{-3}, d=15 \mathrm{~mm}\right)$.

Thus, as depicted in Figures 4-7, the initial location of the inertial particles was set to be the interim space between the blocker plate and the showerhead. We applied zero momentum to the particle motions as an initial condition. This initial condition can be justified because the relaxation time (the time required for a particle to adopt the fluid velocity) of a $1.0 \mu \mathrm{m}$ sized particle (where the particle density is set as $\rho_{p}=2650 \mathrm{~kg} \cdot \mathrm{m}^{-3}$ ) is $6.2 \times 10^{-8} \mathrm{~s}$ [28]. If the maximum gas velocity reaches $125 \mathrm{~m} \cdot \mathrm{s}^{-1}$ at the centerline of the showerhead hole, the particle will travel a distance of $7.8 \times 10^{-6} \mathrm{~m}$ to adopt the gas velocity. As a result, this distance is normally much shorter than the length of the showerhead hole.

Based on the above facts, the particles adopt the gas velocity before leaving the showerhead and entering the process volume (the space between the showerhead and the heater). Therefore, the calculation of the particle trajectory inside the reactor is not affected by this initial condition. Particles that impinged upon the reactor surfaces were assumed to be perfectly absorbed: the sticking coefficient of the particle was set to be 1.0. For Cases 3, 4, and 5, Cases 6, 7, and 8, Cases 9, 10, and 11, and Cases 12,13, and 14, the final positions of particles deposited on the heater surface are depicted in Figures 4-7, respectively.

At the same time, as depicted in Figure 3, the gas accelerates until it reaches the vicinity of the shower radius $\left(r \leq r_{h}=154.3 \mathrm{~mm}\right)$ because the total gas flux at the inlet of the process volume must be the same as that at the side of the inter-electrode region. The radial increase is qualitatively in accordance with the analytical work described by Howling et al. Based on the principle of mass conservation because the maximum gas velocity $\left(V_{\max }\right)$ in the process volume is related to the electrode spacing, larger electrode spacing results in a lower $V_{\max }$. As depicted in Figures 4-7, although the magnitude of the velocity is clearly observed to undergo radial variation between the showerhead and the heater, the formation of deposited particles on the heater is not affected by the radial variation in the magnitude of the velocity: the formation of the deposited particles is not accompanied by radial variations. In addition, regardless of both the particle size and the electrode spacing, the formed particles are commonly randomly scattered. However, the number of deposited particles is different in each case: larger and heavier particles are deposited on the heater more efficiently. 
Note that for PECVD process pressures between 0.1 and 10.0 Torr, the transportation of a neutral gas can be considered to be continuous, viscous, and laminar. In this study, the laminar flow is sufficiently guaranteed because the gas pressure ensures that the overall gas density (i.e., $\rho$ in Equation (1)) remains sufficiently low, and thus the Reynolds number (Re) remains small. Based on the overall density $\left(\rho=3.1 \times 10^{-4} \mathrm{~kg} \cdot \mathrm{m}^{-3}\right)$, the characteristic velocity (the spatially averaged velocity, $\bar{u}=1.35 \mathrm{~m} \cdot \mathrm{s}^{-1}$ ), the characteristic length (the electrode spacing, $d=0.015 \mathrm{~m})$, and the dynamic viscosity $\left(\mu=3.39 \times 10^{-5} \mathrm{~kg} \cdot \mathrm{m}^{-1} \cdot \mathrm{s}^{-1}\right)$, we calculated the Reynolds number $(\operatorname{Re}=\rho \bar{u} d / \mu)$ to be only 0.185 inside the process volume. Therefore, even in the gas inlet manifold, turbulent effects would not be expected to exist, and thus the randomly scattered formation of deposited particles is caused mainly by both the three-dimensional complex structure and the inertial effects of massive particles.

In summary, the gas flows and transportation of inertial particles were analyzed in a three-dimensional complex geometry. Our results revealed that large particles (i.e., $r_{p}>1 \mu \mathrm{m}$ ) can be deposited on the heater surface with the help of the acceleration effects inside the showerhead holes, thus "maintaining the cleanliness" of the gas distribution assembly would be necessary to enhance the productivity of the showerhead reactor.

\section{Discussion}

As the electrode spacing regulates the spatial distribution of the plasma potential and the gas residence time, it is important to investigate the distribution characteristics of the plasma parameters by varying the electrode spacing. Based on the overall mass continuity and the conservation of momentum equations, larger electrode spacings are associated with longer residence time; therefore, $\mathrm{SiH}_{4}$ is expected to be depleted more efficiently with a larger electrode spacing. Thus, in this section, we discuss the effect of electrode spacing on particle generation in plasma discharges. For the validation of our CCP model, in Figure 8, the deposition rate profiles are plotted for Cases $15(d=15 \mathrm{~mm})$ and $16(d=20 \mathrm{~mm})$ (the detailed input conditions are provided in Table 1$)$, and the experimental data are superimposed: the deposition rate profiles are affected by the electrode spacing. To compare the spatial features conveniently, we normalized the profiles with their corresponding averaged values. Note that regardless of the electrode spacing, the simulated deposition rate profiles are in suitable agreement with the corresponding experimental data.

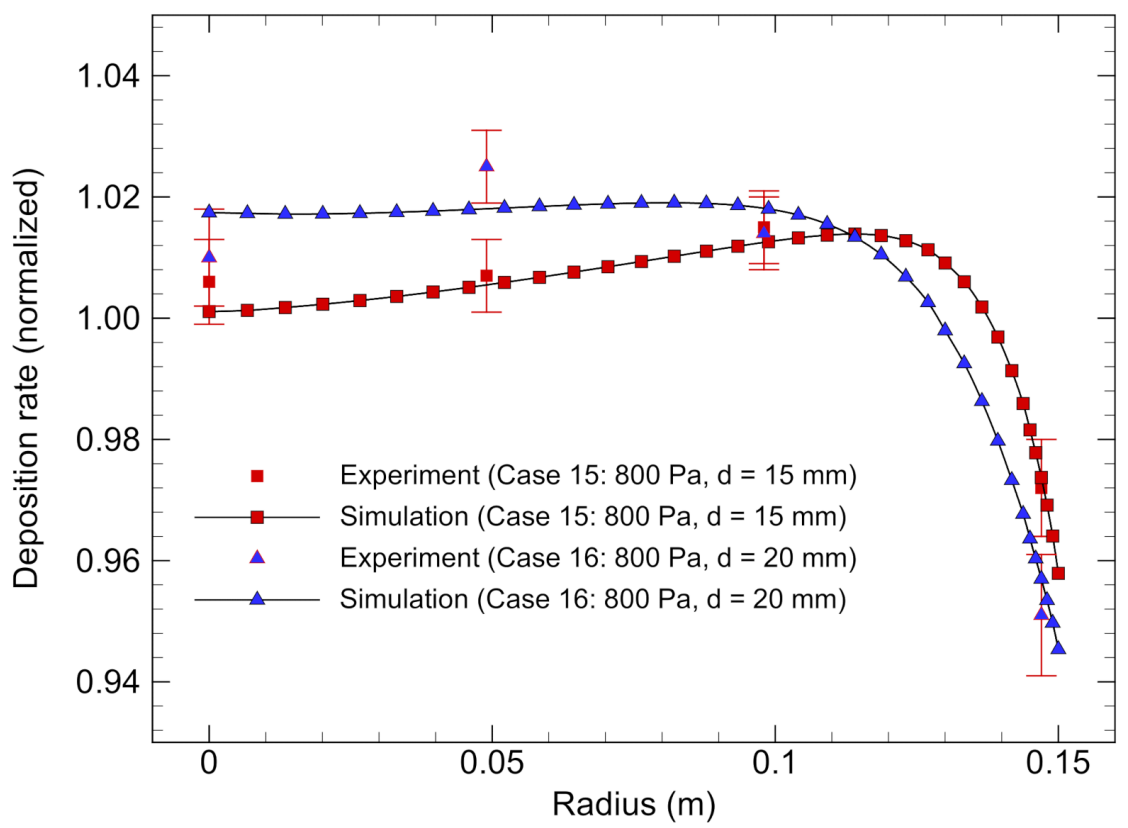

Figure 8. Effect of the electrode spacing on the deposition rate. Deposition rate profiles for Cases 15 $(d=15 \mathrm{~mm})$ and $16(d=20 \mathrm{~mm})$ are plotted. 
As higher gas pressure accelerates particle growth in the gas phase, the gas pressure was set as $p_{g}=2400 \mathrm{~Pa}$ in Cases 17 and 18, which is higher than the gas pressure in Cases 15 and 16. For Cases 17 and 18, Figure 9 demonstrates that smaller electrode spacing negatively affects the efficiency whereby both $\mathrm{Si}_{4} \mathrm{H}_{10}$ and $\mathrm{Si}_{5} \mathrm{H}_{12}$ are generated, and they thus reach the heater surface less easily. Note that it is commonly observed that the density distributions of $\mathrm{Si}_{4} \mathrm{H}_{10}$ and $\mathrm{Si}_{5} \mathrm{H}_{12}$ are initially low at the showerhead inlet and increase as they approach the bulk plasma region. The thicknesses of the diffusion layers formed near the showerhead inlet increase slightly with smaller electrode spacing.

(a)

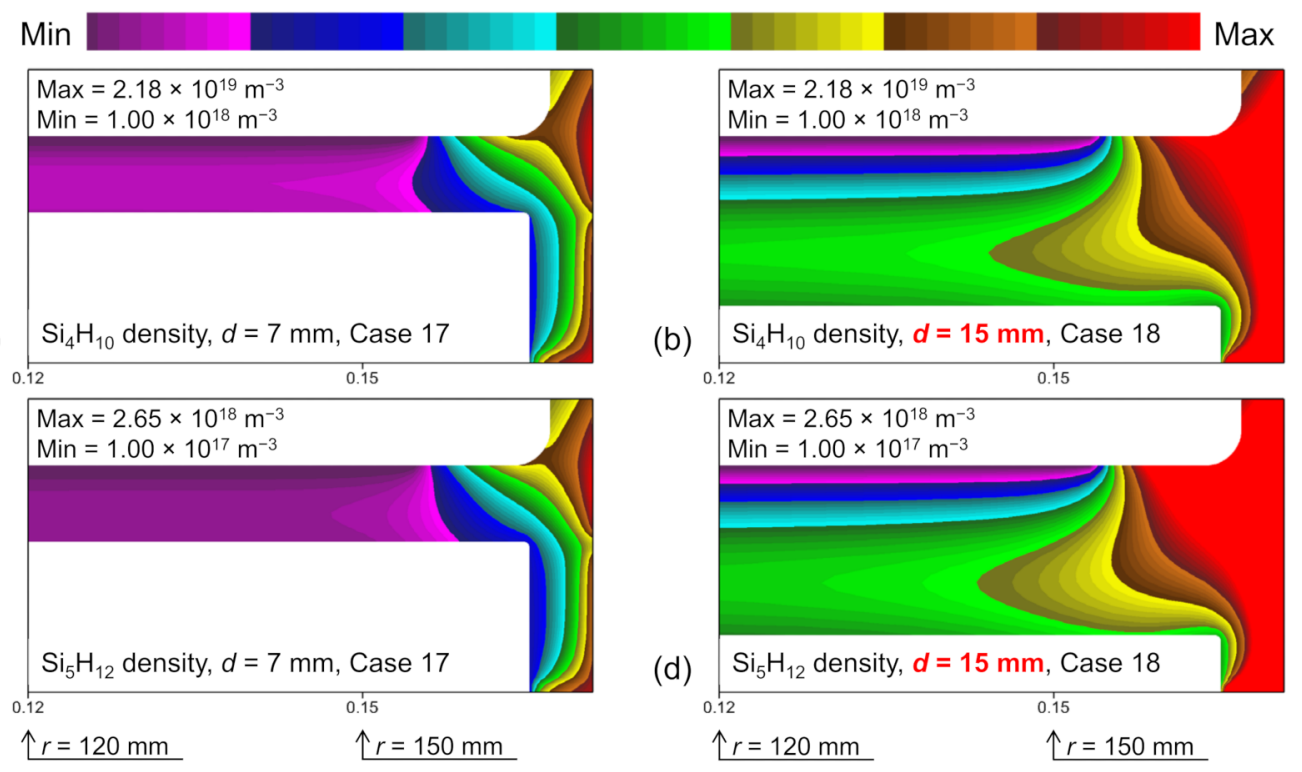

Figure 9. Contour plots of the spatial profiles of the time-averaged $\mathrm{Si}_{4} \mathrm{H}_{10}$ density $\left(\mathrm{m}^{-3}\right)$ for (a) Case $17(d=7 \mathrm{~mm})$ and $(\mathbf{b})$ Case $18(d=15 \mathrm{~mm})$ for $r \geq 120 \mathrm{~mm}$. Contour plots of the spatial profiles of the time-averaged $\mathrm{Si}_{5} \mathrm{H}_{12}$ density $\left(\mathrm{m}^{-3}\right)$ for $(\mathbf{c})$ Case $17(d=7 \mathrm{~mm})$ and $(\mathbf{d})$ Case $18(d=15 \mathrm{~mm})$ for $r \geq 120 \mathrm{~mm}$. The profiles are radially uniform for $r<120 \mathrm{~mm}$.

With respect to the novelty of the outcome of this study, we conducted three-dimensional CFD simulations to understand the hydrodynamic effects induced by the real geometry of the reactor: the geometries that were considered were set exactly by minimizing simplification. In addition, the extent to which the particle size and electrode spacing affect the efficiency of particle deposition was numerically investigated in detail in this study. Our results indicated that the smaller electrode spacing promotes the deposition on the heater of particles fed from the showerhead, whereas the larger electrode spacing facilitates the deposition on the heater of particles generated in the plasma volume.

\section{Conclusions}

We investigated ways in which to enhance productivity by conducting a computational fluid dynamics analysis of the extent to which particle deposition is induced by the showerhead, which acts as both the gas distributor and the electrode in a showerhead-type CCP deposition reactor. We simulated the particle transport phenomena in a three-dimensional complex geometry. However, $\mathrm{SiH}_{4} / \mathrm{He}$ discharges were simulated in a two-dimensional simplified geometry. The particle transport simulation did not take the CCP discharges into consideration because of the extremely high computational cost. The process volume was located between the RF-powered showerhead and the grounded heater.

Particle trajectories were calculated by releasing inertial particles with zero momentum from the initial positions for Cases $3\left(r_{p}=2.0 \times 10^{-6} \mathrm{~m}, \rho_{p}=2329 \mathrm{~kg} \cdot \mathrm{m}^{-3}, d=9 \mathrm{~mm}\right)$, $4\left(r_{p}=4.0 \times 10^{-6} \mathrm{~m}, \rho_{p}=2329 \mathrm{~kg} \cdot \mathrm{m}^{-3}, d=9 \mathrm{~mm}\right), 5\left(r_{p}=6.0 \times 10^{-6} \mathrm{~m}, \rho_{p}=2329 \mathrm{~kg} \cdot \mathrm{m}^{-3}\right.$, $d=9 \mathrm{~mm})$, Cases $6\left(r_{p}=2.0 \times 10^{-6} \mathrm{~m}, \rho_{p}=2329 \mathrm{~kg} \cdot \mathrm{m}^{-3}, d=15 \mathrm{~mm}\right), 7\left(r_{p}=4.0 \times 10^{-6} \mathrm{~m}\right.$, 
$\left.\rho_{p}=2329 \mathrm{~kg} \cdot \mathrm{m}^{-3}, d=15 \mathrm{~mm}\right), 8\left(r_{p}=6.0 \times 10^{-6} \mathrm{~m}, \rho_{p}=2329 \mathrm{~kg} \cdot \mathrm{m}^{-3}, d=15 \mathrm{~mm}\right)$, Cases 9 $\left(r_{p}=2.0 \times 10^{-6} \mathrm{~m}, \rho_{p}=2650 \mathrm{~kg} \cdot \mathrm{m}^{-3}, d=9 \mathrm{~mm}\right), 10\left(r_{p}=4.0 \times 10^{-6} \mathrm{~m}, \rho_{p}=2650 \mathrm{~kg} \cdot \mathrm{m}^{-3}\right.$, $d=9 \mathrm{~mm}), 11\left(r_{p}=6.0 \times 10^{-6} \mathrm{~m}, \rho_{p}=2650 \mathrm{~kg} \cdot \mathrm{m}^{-3}, d=9 \mathrm{~mm}\right)$, and Cases $12\left(r_{p}=2.0 \times 10^{-6} \mathrm{~m}\right.$, $\left.\rho_{p}=2650 \mathrm{~kg} \cdot \mathrm{m}^{-3}, d=15 \mathrm{~mm}\right), 13\left(r_{p}=4.0 \times 10^{-6} \mathrm{~m}, \rho_{p}=2650 \mathrm{~kg} \cdot \mathrm{m}^{-3}, d=15 \mathrm{~mm}\right)$, and 14 $\left(r_{p}=6.0 \times 10^{-6} \mathrm{~m}, \rho_{p}=2650 \mathrm{~kg} \cdot \mathrm{m}^{-3}, d=15 \mathrm{~mm}\right)$. The particles were initially positioned in the interim space between the blocker plate and the showerhead. Particles that impinged upon the reactor surfaces were assumed to be perfectly absorbed. Although radial variation in the magnitude of the gas velocity was clearly observed between the showerhead and the heater, the formation of the particles deposited on the heater was not affected by the distribution of the magnitude of the gas velocity. Note that particle deposition on the heater less easily occurs with the larger electrode spacing $(d=15 \mathrm{~mm})$. In addition, regardless of the particle size, particle formation was randomly scattered in all cases. Large particles could be transported to the heater with the help of the acceleration effects inside the showerhead holes. Because the space inside the showerhead is constricted, this limits the space available for particle flow. Thus, high gas velocities within the showerhead holes can accelerate particles and lead to inertia-enhanced particle deposition. This indicates that the cleanliness of the gas distribution assembly should be maintained to enhance the productivity of the reactor.

The effect of the electrode spacing on particle deposition was also investigated. The simulation results were supplemented by conducting a practical PECVD experiment involving the deposition of hydrogenated amorphous silicon (a-Si:H) film (Cases 15 and 16). We additionally demonstrated that when the electrode spacing is smaller, $\mathrm{Si}_{5} \mathrm{H}_{12}$ is generated less efficiently and thus reaches the heater surface less easily (Cases 17 and 18). As a result, we found that the smaller electrode spacing promoted the deposition on the heater of particles fed from the showerhead, whereas the larger electrode spacing facilitated the deposition on the heater of particles generated in the plasma volume. In a future study, we plan to include details of the discharge model to observe the motions of charged particles in the three-dimensional complex geometry. We additionally aim to investigate the motion of non-spherical particles.

Author Contributions: Conceptualization, H.J.K.; Data curation, H.J.K. and J.H.Y.; Formal analysis, H.J.K. and J.H.Y.; Funding acquisition, H.J.K.; Investigation, H.J.K. and J.H.Y.; Methodology, H.J.K.; Project administration, H.J.K.; Resources, H.J.K.; Software, H.J.K.; Supervision, H.J.K.; Validation, H.J.K.; Visualization, H.J.K. and J.H.Y.; Writing—original draft, H.J.K.; Writing-review and editing, H.J.K. All authors have read and agreed to the published version of the manuscript.

Funding: This work was supported by the Gachon University research fund of 2019 (GCU-2019-0814) and the National Research Council of Science \& Technology (NST) grant by the Korea government (MSIT) (No. CRC-20-01-NFRI).

Institutional Review Board Statement: Not applicable.

Informed Consent Statement: Not applicable.

Data Availability Statement: Not applicable.

Conflicts of Interest: The authors declare no conflict of interest.

\section{References}

1. Smith, D.L. Thin-Film Deposition: Principles and Practice; McGraw-Hill: New York, NY, USA, 1995.

2. Street, R.A. Technology and Applications of Amorphous Silicon; Springer: Berlin/Heidelberg, Germany; Springer: New York, NY, USA, 2000.

3. Lieberman, M.A.; Lichtenberg, A.J. Principles of Plasma Discharges and Materials Processing; John Wiley \& Sons Inc.: Hoboken, NJ, USA, 2005.

4. Yavas, O.; Richter, E.; Kluthe, C.; Sickmoeller, M. Wafer-edge yield engineering in leading-edge DRAM manufacturing. Semicond. Fabtech 2009, 35, 1.

5. Hichri, H.; Sippel, J.O.; Grunow, S.L.; Bunke, C.; Kelp, J.; Fang, R.; Kulkarni, D.; Angyal, M.; Houghton, T.; Santiago, A.; et al. Integration solutions for $65 \mathrm{~nm}$ back end of line defect reduction and manufacturability. J. ECS Trans. 2007, 11, 265-275. [CrossRef]

6. Menz, W.J.; Kraft, M. A new model for silicon nanoparticle synthesis. Combust. Flame 2013, 160, 947-958. [CrossRef] 
7. Rader, D.J.; Geller, A.S. Showerhead-enhanced inertial particle deposition in parallel-plate reactors. Aerosol Sci. Technol. 1998, 28, 105-132. [CrossRef]

8. Nijhawan, S.; McMurry, P.H.; Campbell, S.A. Particle transport in a parallel-plate semiconductor reactor: Chamber modification and design criterion for enhanced process cleanliness. J. Vac. Sci. Technol. A 2000, 18, 2198-2206. [CrossRef]

9. Hash, D.B.; Mihopoulos, T.; Govindan, T.R.; Meyyappan, M. Characterization of showerhead performance at low pressure. J. Vac. Sci. Technol. B 2000, 18, 2808-2813. [CrossRef]

10. Sansonnens, L.; Howling, A.A.; Hollenstein, C. A gas flow uniformity study in large-area showerhead reactors for RF plasma deposition. Plasma Sources Sci. Technol. 2000, 9, 205. [CrossRef]

11. Sobbia, R.; Sansonnens, L.; Bondkowski, J. Uniformity study in large-area showerhead reactors. J. Vac. Sci. Technol. A 2005, 23, 927-932. [CrossRef]

12. Howling, A.A.; Legradic, B.; Chesaux, M.; Hollenstein, C. Plasma deposition in an ideal showerhead reactor: A two-dimensional analytical solution. Plasma Sources Sci. Technol. 2012, 21, 015005. [CrossRef]

13. Setyawan, H.; Shimada, M.; Ohtsuka, K.; Okuyama, K. Visualization and numerical simulation of fine particle transport in a low-pressure parallel plate chemical vapor deposition reactor. Chem. Eng. Sci. 2002, 57, 497-506. [CrossRef]

14. Setyawan, H.; Shimada, M.; Imajo, Y.; Hayashi, Y.; Okuyama, K. Characterization of particle contamination in process steps during plasma-enhanced chemical vapor deposition operation. J. Aerosol. Sci. 2003, 34, 923-936. [CrossRef]

15. Setyawan, H.; Shimada, M.; Hayashi, Y.; Okuyama, K.; Yokoyama, S. Particle formation and trapping behavior in a TEOS/O 2 plasma and their effects on contamination of a Si wafer. Aerosol Sci. Technol. 2004, 38, 120-127. [CrossRef]

16. Kim, H.J.; Yang, W.; Joo, J. Effect of electrode spacing on the density distributions of electrons, ions, and metastable and radical molecules in $\mathrm{SiH}_{4} / \mathrm{NH}_{3} / \mathrm{N}_{2} / \mathrm{He}$ capacitively coupled plasmas. J. Appl. Phys. 2015, 118, 043304. [CrossRef]

17. Kim, H.J.; Lee, H.J. Analysis of intermediate pressure $\mathrm{SiH}_{4} / \mathrm{He}$ capacitively coupled plasma for deposition of an amorphous hydrogenated silicon film in consideration of thermal diffusion effects. Plasma Sources Sci. Technol. 2017, 26, 085003. [CrossRef]

18. Morsi, S.A.; Alexander, A.J. An investigation of particle trajectories in two-phase flow systems. J. Fluid Mech. 1972, 55, 193-208. [CrossRef]

19. Simerics Inc. Available online: https:/ / www.simerics.com (accessed on 30 July 2021).

20. Patankar, S.V. Numerical Heat Transfer and Fluid Flow; Routledge: London, UK, 1980.

21. Kim, H.J.; Beskok, A. An algebraic factorisation scheme for spectral element solution of incompressible flow and scalar transport. Int. J. Comp. Fluid Dyn. 2010, 24, 95-108. [CrossRef]

22. ESI Group. CFD-ACE+ 2020.0 Manual; ESI US R\&D Inc.: Huntsville, AL, USA, 2020.

23. Farouk, T.; Farouk, B.; Staack, D.; Gutsol, A.; Fridman, A. Simulation of dc atmospheric pressure argon micro glow-discharge. Plasma Sources Sci. Technol. 2006, 15, 676-688. [CrossRef]

24. Farouk, T.; Farouk, B.; Gutsol, A.; Fridman, A. Atmospheric pressure methane-hydrogen dc micro-glow discharge for thin film deposition. J. Phys. D Appl. Phys. 2008, 41, 175202. [CrossRef]

25. Danko, S.; Bluhm, D.; Bolsinger, V.; Dobrygin, W.; Schmidt, O.; Brinkmann, R.P. A global model study of silane/hydrogen discharges. Plasma Sources Sci. Technol. 2013, 22, 055009. [CrossRef]

26. Zhang, B.; Zhang, X. Control of higher-silane generation by dilution gases in $\mathrm{SiH}_{4}$ plasmas. Plasma Sources Sci. Technol. 2020, 29, 095012. [CrossRef]

27. Agarwal, A.; Rauf, S.; Collins, K. Gas heating mechanisms in capacitively coupled plasmas. Plasma Sources Sci. Technol. 2012, 21, 055012. [CrossRef]

28. Bird, R.B.; Stewart, W.E.; Lightfoot, E.N. Transport Phenomena; John Wiley \& Sons, Inc.: New York, NY, USA, 2007. 